Provided for non-commercial research and education use. Not for reproduction, distribution or commercial use.

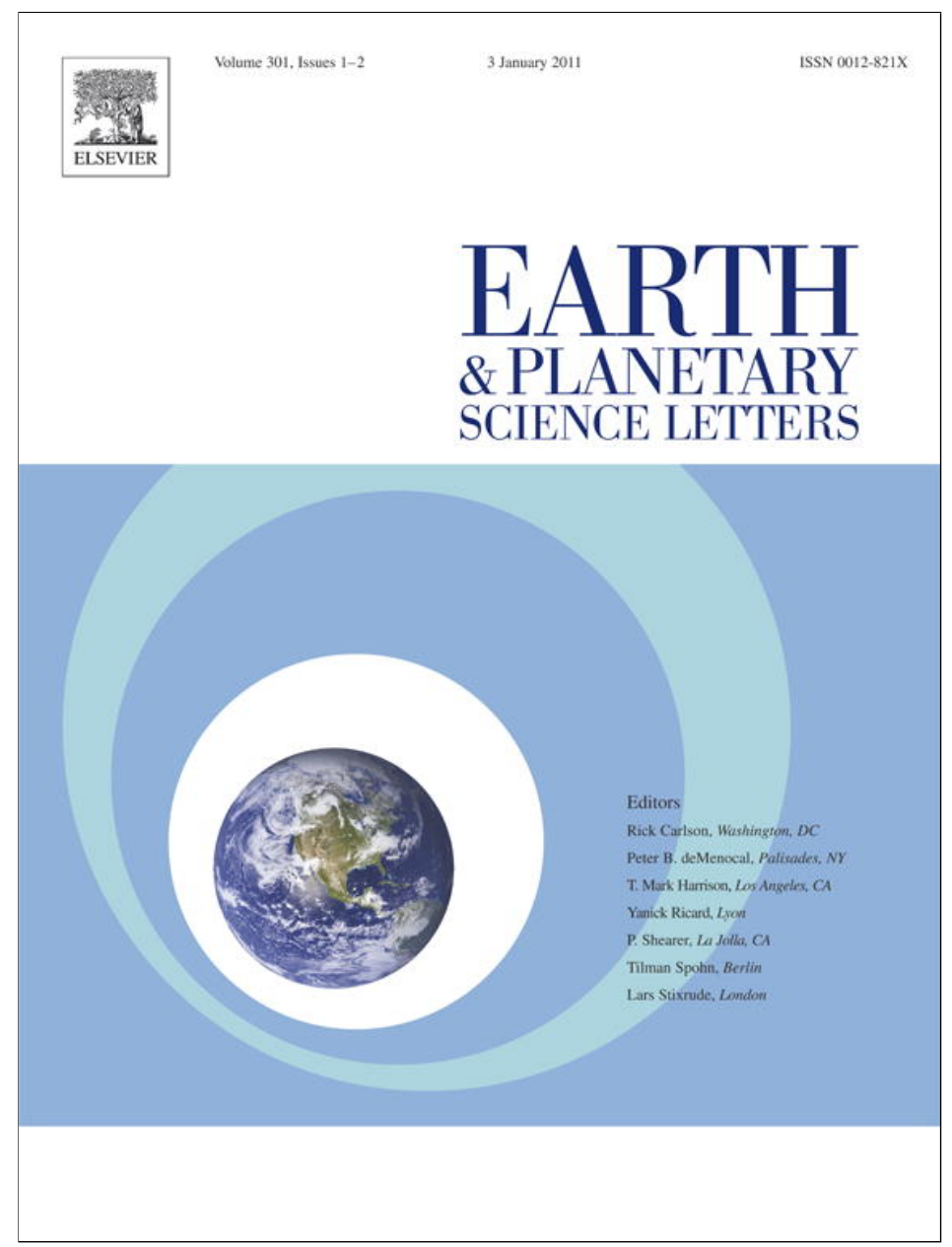

(This is a sample cover image for this issue. The actual cover is not yet available at this time.)

This article appeared in a journal published by Elsevier. The attached copy is furnished to the author for internal non-commercial research and education use, including for instruction at the authors institution and sharing with colleagues.

Other uses, including reproduction and distribution, or selling or licensing copies, or posting to personal, institutional or third party websites are prohibited.

In most cases authors are permitted to post their version of the article (e.g. in Word or Tex form) to their personal website or institutional repository. Authors requiring further information regarding Elsevier's archiving and manuscript policies are encouraged to visit:

http://www.elsevier.com/copyright 


\title{
Recent tectonics and subsidence on Mars: Hints from Aureum Chaos
}

\author{
Mauro G. Spagnuolo a,*, Angelo Pio Rossi ${ }^{\text {b,c }}$, Ernst Hauber ${ }^{\mathrm{d}}$, Stephan van Gasselt ${ }^{\mathrm{e}}$ \\ a IDEAN, UBA-CONICET, Ciudad de Bs. As., Argentina \\ b International Space Science Institute, Hallerstrasse 6, CH-3012, Bern, Switzerland \\ c Department of Earth and Space Sciences, Jacobs University Bremen, Campus Ring 1, 28759 Bremen, Germany \\ ${ }^{d}$ Institut für Planetenforschung/Institute of Planetary Research, German Aerospace Center (DLR), 12489 Berlin, Germany \\ e Freie Universität Berlin, Institut für Geologische Wissenschaften, Malteserstr. 74-100, Haus D-232, D-12249 Berlin, Germany
}

\section{A R T I C L E I N F O}

\section{Article history:}

Received 27 June 2011

Received in revised form 27 September 2011

Accepted 29 September 2011

Available online $\mathrm{xxxx}$

Editor: P. Shearer

\section{Keywords:}

Mars

neotectonics

Aureum Chaos

Light Tone Deposits

subsidence

\begin{abstract}
A B S T R A C T
High spatial and spectral resolution imagery and topography collected during the last decade are changing our vision of Mars into that of a geologically active planet, even in recent times. However, the connection between internal activity such as faulting and other recent geomorphic processes and deposits, such as eolian or mass wasting units, is difficult to establish. In this work we study a geomorphic feature located inside Aureum Chaos $\left(4^{\circ} \mathrm{S}, 333^{\circ} \mathrm{E}\right)$ which is situated at the dichotomy boundary between southern highlands and northern lowlands on Mars. We identified fault-related activity based on HIRISE imagery and mapped a landslide of LTD (Light Tone Deposits) material which seems to be modified by a fault. Displacement measurements across the scarp are in agreement with values measured in other Amazonian-aged extensional settings on Mars. Moreover, the relation between landslide and eolian material shows that it was produced very recently in time, since the activity seems to postdate a dune field whose age was determined to be less than $1.9 \mathrm{Myr}$ old. This observation together with other scarp-related activity near the area suggests that very recent subsidence activity has occurred along previous fault planes inside Aureum Chaos.
\end{abstract}

(c) 2011 Elsevier B.V. All rights reserved.

\section{Introduction}

Mars's recent evolution is dynamic, both with respect to its climate change (e.g., Dohm et al., 2008, Head et al., 2003) and its possibly very young volcanic activity (e.g. Basilevsky et al., 2006; Hauber et al., 2011; Neukum et al., 2004). Although most of the recent geological processes are associated with exogenic activity like wind-sediment interaction (Silvestro et al., 2010), or volatile-related activity (Diniega et al., 2010; Kereszturi et al., 2009; McEwen et al., 2011; Morgan et al. 2008; Reiss et al., 2004), relatively young tectonic activity has also been suggested (Knapmeyer et al., 2006) from large-scale observations and modeling of seismicity. Evidence of recent tectonic activity also arises from the study of landslides. Quantin et al. (2004) showed that landslides in Valles Marineris could be as young as $50 \mathrm{Myr}$. The same authors also proposed that those landslides are related to tectonic seismicity.

The links between endogenic activity and geomorphic features on Mars, such as eolian or mass wasting deposits, are difficult to establish, although they can be found in some key areas (Marquez et al. 2004). Here we present observational evidence of very recent subsidence on Mars by analyzing affected layered deposits inside Aureum Chaos basin and cross-cutting relations between scarps, dunes and landslides.

\footnotetext{
* Corresponding author at: IDEAN UBA-CONICET Departamento de Geología Intendente Güiraldes 2160 - Ciudad Universitaria, Pabellon2 - C1428EGA - Ciudad de Bs. As. Argentina. Tel.: + 541145763300 .

E-mail address: mgspag@gmail.com (M.G. Spagnuolo).
}

\section{Methods and approaches}

In this study we mainly used morphologic and morphometric mapping in order to evaluate our hypothesis. We produced a detailed map using HIRISE image PSP_006004_1765, of a key area where we identified a landslide possibly affected by extensional tectonics. We then attempted to reconstruct a chronology of the events based on cross-cutting relations of the identified units and crater counting. Since a lack of craters in the area prevented us to properly constrain the age of some units, we extended our analysis toward the north-east using another HIRISE image (PSP_003103_1765) to identify overlapping relations with cratered units. Moreover, we used topography information from MOLA and higher-resolution DEM (Digital Elevation Models) to establish the main stratigraphy, and to propose a structural model. Finally we looked for a terrestrial analog to evaluate our hypothesis.

\section{Geology and geomorphology background}

Aureum Chaos $\left(4^{\circ} \mathrm{S}, 333^{\circ} \mathrm{E}\right)$ is located near the boundary between the southern highlands and northern lowlands on Mars, east of Valles Marineris and south of the main chaotic terrain-outflow channel systems (Nelson and Greeley, 1999). It is a confined complex basin, adjacent to the smaller Arsinoe Chaos, and it likely formed in the context of pre-existing paleo-impact basins (Rodriguez et al., 2005, 2006). Its topography ranges between -1800 and $-4100 \mathrm{~m}$ below Mars' aeroid, its diameter is about $370 \mathrm{~km}$, and it occupies an area of $71,000 \mathrm{~km}^{2}$. 
As with other chaotic terrains on Mars, Aureum Chaos formation dates back to the Lower Hesperian (Nelson and Greeley, 1999) and its evolution was probably complex and not linked to a single outflow episode (Rodriguez et al., 2005) (Fig. 1). The geodynamical context of the actual chaotic terrain formation mechanism is still debated (e.g., Meresse et al., 2008; Zegers et al., 2010). The regional geomorphology is dominated by relatively large mesas and knobs distributed over the floor of Aureum Chaos. Several outcrops of light-toned deposits (LTD) in Aureum Chaos lie stratigraphically on top of chaos mesas and knobs. They are suggested to be of sedimentary nature (Glotch and Rogers, 2007; Rossi et al., 2008) and they do show spectral evidence of various assemblages of hydrated minerals (Dobrea et al., 2008). Eolian deposits are ubiquitous in low-lying areas, e.g., inter-knob depressions, and they consist largely of sand sheets, dunes, and transverse eolian ridges (Balme et al., 2008).

LTDs are variably eroded and etched on their upper surface, while their contact with lower units (bedrock, mesas/knobs) is often characterized by unconformity relations. The deposits are also characterized by steep rectilinear or sub-rectilinear scarps. The study area is located in the central portion of Aureum Chaos, at the edge of one of these scarps bordering a stack of LTDs (Fig. 1).

\section{Observations}

\subsection{Geology and geomorphology}

The main investigation area is characterized by a topographic step of $480 \mathrm{~m}$. Three main morphological domains were recognized: a) high plateau domain, b) foothill domain, and c) foothill regional level.

The high plateau domain is characterized by outcrops of LTD which represent the free-face scarp of the high plateau. "Crater Ejecta" deposits form the oldest unit identified based on crater counts and by stratigraphic relations. They are located at the top of the high plateau and represent the ejecta material from an impact crater immediately to the north-east (Fig. 1). Above this unit we identified the "Eolian
Plateau Deposits" consisting of a darker and less rough material which covers "Crater Ejecta".

The foothill domain is characterized by mass-wasting and eolian deposits. "Landslide Deposits" represent a unit with a rounded shape in plan view, which is located at the foot of a headscarp with a total area of $0.24 \mathrm{~km}^{2}$. It displays light-toned albedo and rough texture. It also exhibits parallel crests transverse to the displacement direction of the landslide, which might have been initially formed as contractional pressure ridges, possibly later reshaped by eolian activity (Fig. 2a). Based on these morphological aspects and the association with nearby mass wasting processes and location beneath a head-scarp we interpret it as a landslide, possibly an avalanche deposit. This unit is split by a central fracture. Also just above the landslide, there is a rectangular block of LTD displaced from its original position, just below a small headscarp, that could be a potential displaced block. Two distinct detrital cone-type deposits were recognized. Most of the debris cones are found at the termination of deep vertical-wall depressions, associated with debris fall. They are characterized by the absence of gullies and incisions (Fig. 2b). These detrital cones were separated in two units based on position and morphology: a) "Debris Cone I" represents light-toned cones with rough texture which resemble "Landslide deposits", and b) "Debris Cone II" represents dark smooth cones most likely composed by sediments from "Eolian Plateau Deposits" above LTD and/or inter-layer finegrained material. "Eolian Graben Infill" represent a cover of linear dark dunes inside a linear depression at the foot of the scarp. Finally, the foothill regional level is dominated by dark material composed of transverse dunes which were mapped as "Dune Field" and "Eolian Graben Infill". From the termination of the East-scarp a "Dark Sheet Material" extends and fills the interdune area of the "Eolian Graben Infill".

\subsection{Scarp description and structure}

LTD deposits show a West-facing scarp trending N-S. It has an elevation difference of $480 \mathrm{~m}$, measured in a HRSC-derived DEM. In a very
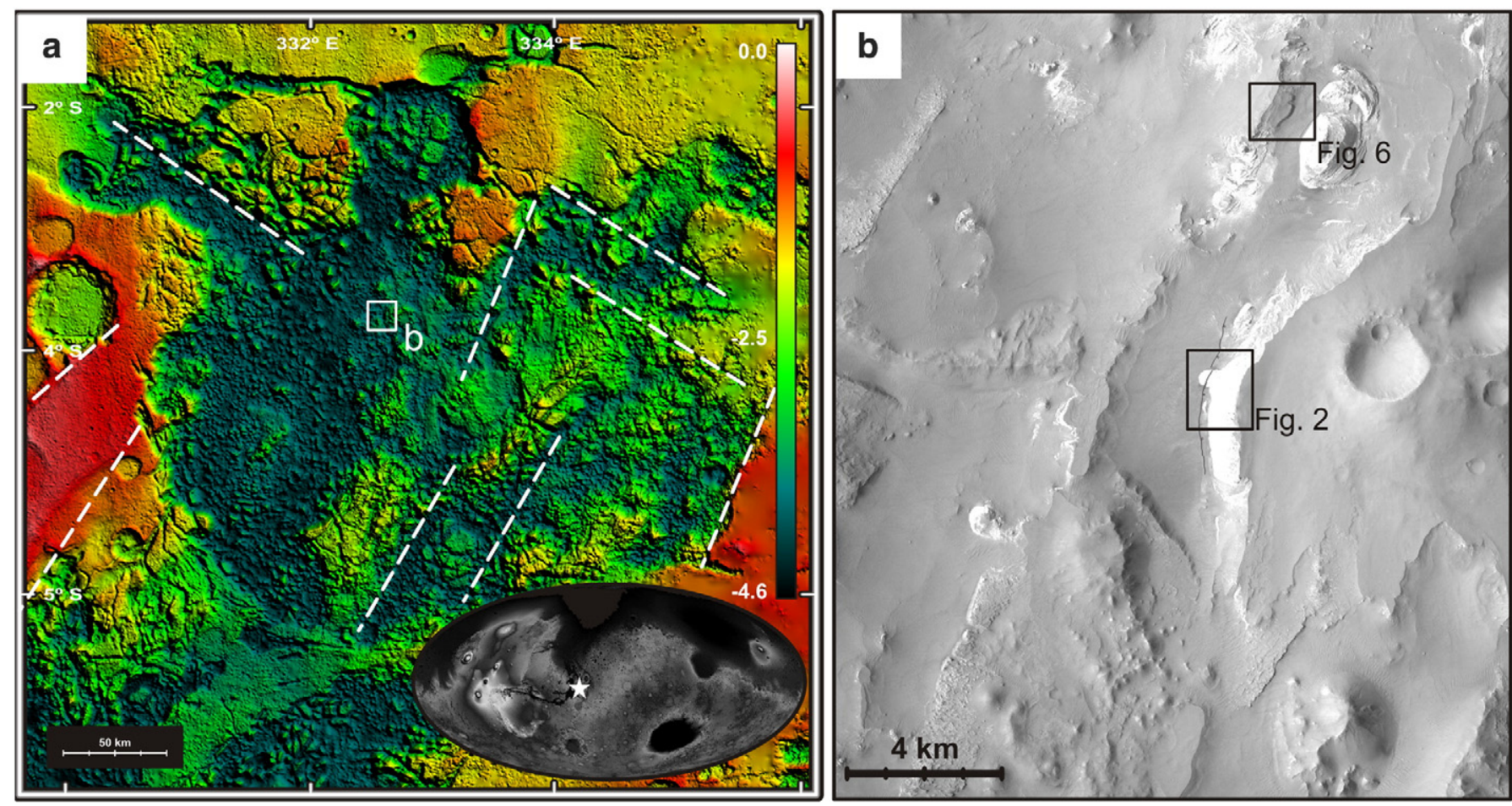

Fig. 1. The study area in Aureum Chaos. (a) Shaded-relief view derived from a mosaic of HRSC stereo observations. Dashed lines show main linear features that might be related to structural control. Scale bar on the right indicates elevation in kilometers. Inset in lower right shows location on Mars. (b) Regional context of the study sites, centered at $03.64^{\circ} \mathrm{S}$ and $332.60^{\circ} \mathrm{E}$ (detail of CTX image P04_002536_1757). 

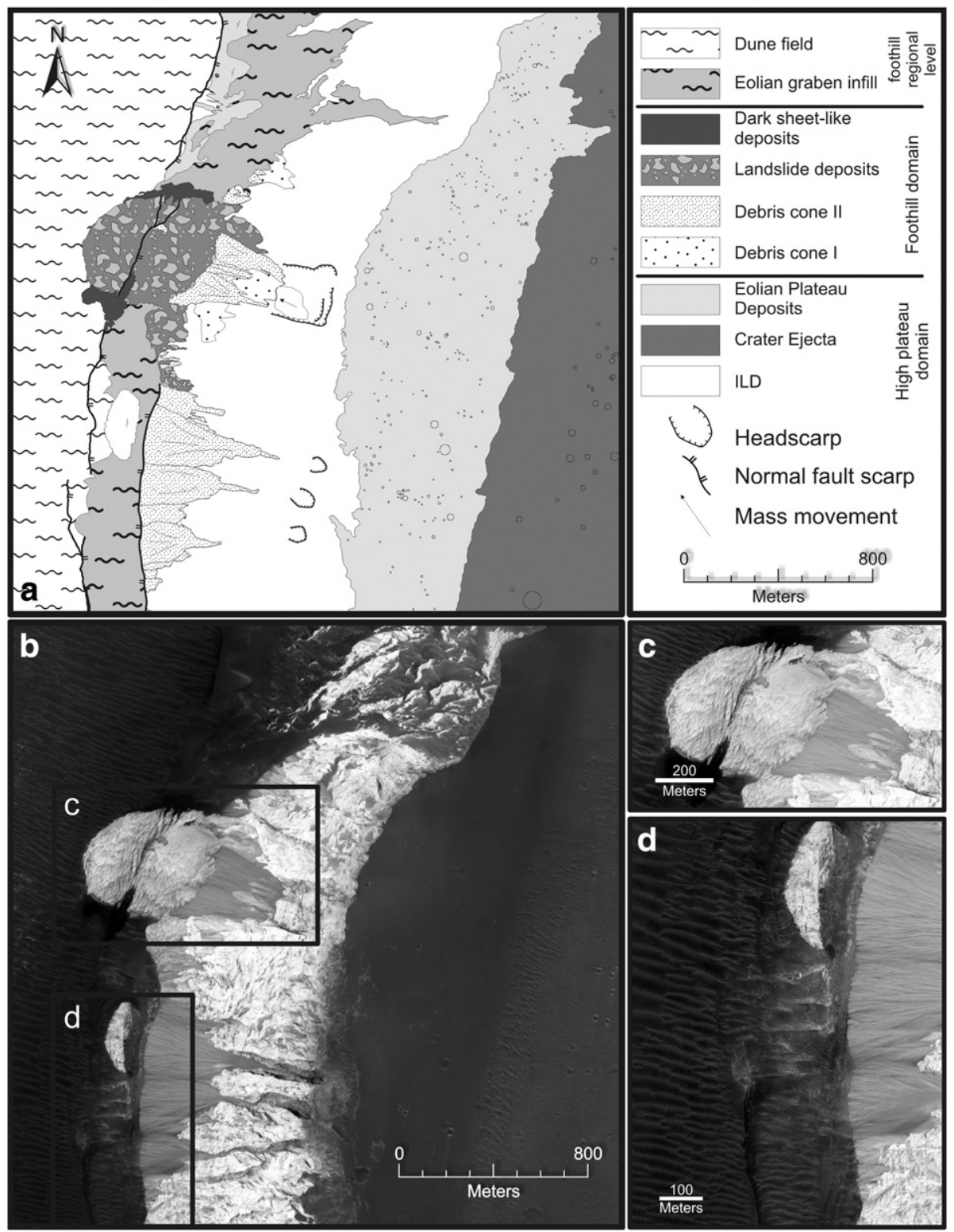

Fig. 2. (a) Geomorphologic sketch map of the area, (b) image view of the landslide affected by a central fracture. See location in Fig. 1. (c) Detail of landslide with linear crack. (d) Detail of the linear scarp aligned with landslide fracture in (b). (c-d) Details of HIRISE image PSP_006004_1765.

high-resolution HIRISE image (PSP_006004_1765) a small parallel antithetic scarp can be identified. This small scarp is highlighted not only by its shadow but also by the morphology of the dunes that emphasize the linear pattern. This East-facing scarp shows no evidence of degradation on the images and its vertical offset is considerably smaller than that of the West-facing main scarp and does not have a vertical expression on the HRSC-derived DEM (Fig. 3). A MOLA track that crosses the area confirms that both scarps delineate a linear parallel depression. This depression is filled with debris material and fallen blocks from the LTD stack, together with eolian deposits. The landslide described in the previous section is affected by a series of fractures exactly in the trace of the East-facing scarp. The West-facing scarp also shows variations in slope along strike (Fig. 3). The landslide deposit and possibly more recent debris aprons are located where the scarp shows the steepest slopes, between $11^{\circ}$ and $15^{\circ}$, as measured in the HRSC-derived DEM (Fig. 3).

\subsection{Age relationships}

The relation between scarp and dune field is ambiguous and no clear interaction between the landslide and the dunes is observed. Dark sand sheet-like deposits can be seen in the HIRISE image on both sides of the fracture cutting the landslide but no eolian deposits or dunes are found inside the fracture although disaggregated material can be found forming small debris aprons. The principal evidence that some activity postdates the dune deposits is that some dunes are cut by the scarp showing their crests broken appart (Fig. 4). Moreover, the dune pattern on both sides of the scarp is almost the same but no falling dunes or debris are found in the scarp, as should be expected if the dune field postdates the scarp. In summary, we conclude that the fractures cutting the landslide deposit are related to the East-facing scarp, since both are following the same trend and although the relative age between the landslide and the dunes cannot be determined, there are clear evidences that activity of the East-facing antithetic scarp post-dates and affects both, the landslide and dunes.

\subsection{Crater size-frequency dating}

Neither the landslide nor the postdating debris aprons are superimposed by impact craters that would directly allow measurements of their age. Materials from the top of the plateau and an identified 

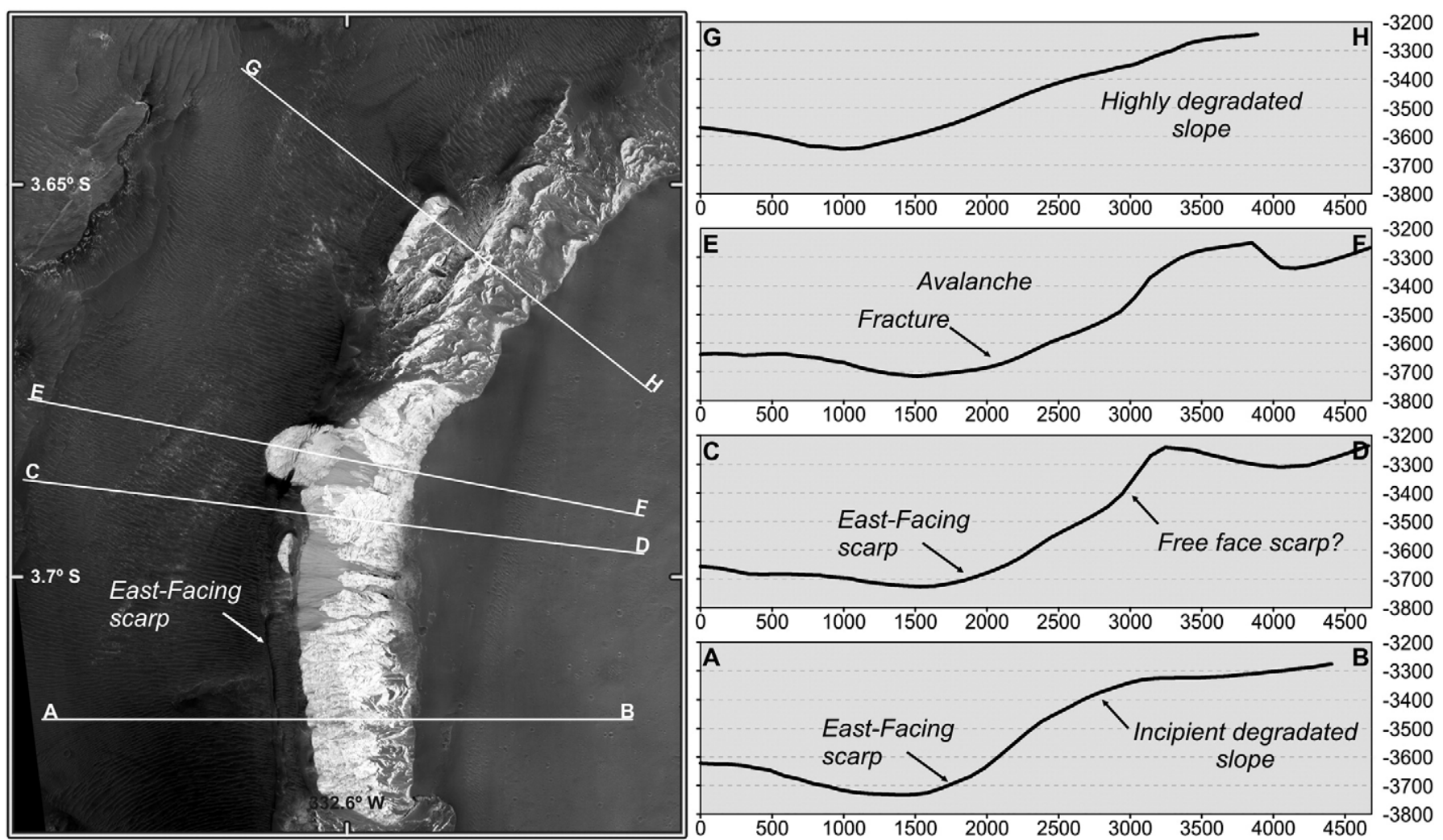

Fig. 3. Vertical profiles derived from HRSC DEM that show a progressively more degraded scarp toward the North. Note that steeper slopes are found near the faulted landslide.

surface partially covered by dunes, however, do show craters which can be dated by crater counting to assign maximum ages (see location in Ancillary Fig. 1).

Subscenes of HRSC images were prepared for statistical analysis of the crater-size frequency distributions in order to obtain absolute crater model ages. The cumulative plots were made using the software CraterTools (Kneissl et al., 2011) and Craterstats II (Michael and Neukum, 2010). We present the results from counting in a cumulative crater frequency plot, applying the production function coefficients of Ivanov (2001) and the impact-cratering chronology model coefficients of Hartmann and Neukum (2001). The relative absence of impact craters required us to count even small craters with diameters $<100 \mathrm{~m}$, avoiding recognizable clusters or chains (McEwen and Bierhaus, 2006). Despite a possible role of secondary craters (e.g.,
McEwen et al., 2005), at least two of the model ages fit to isochrons. In fact, Werner et al. (2009) and Hartmann et al. (2010) demonstrated that the effects of secondary cratering do not prevent the use of small $(<100 \mathrm{~m})$ craters for absolute age determination. Only the cumulative distribution of "Crater Ejecta" material shows a deviation of the curve from the isochron at larger diameters, a fact that could be attributed to some resurfacing event (Michael and Neukum, 2010). This would not change our results because our focus is on the youngest surface units, and a possible older, buried surface would not alter the relative and absolute ages of the younger units.

Crater counting in the "Crater Ejecta" material and "Eolian Plateau Deposits" resulted in ages of $7.74 \mathrm{Ma}$ and $4.43 \mathrm{Ma}$, respectively, which is in agreement with their stratigraphic relation. There are

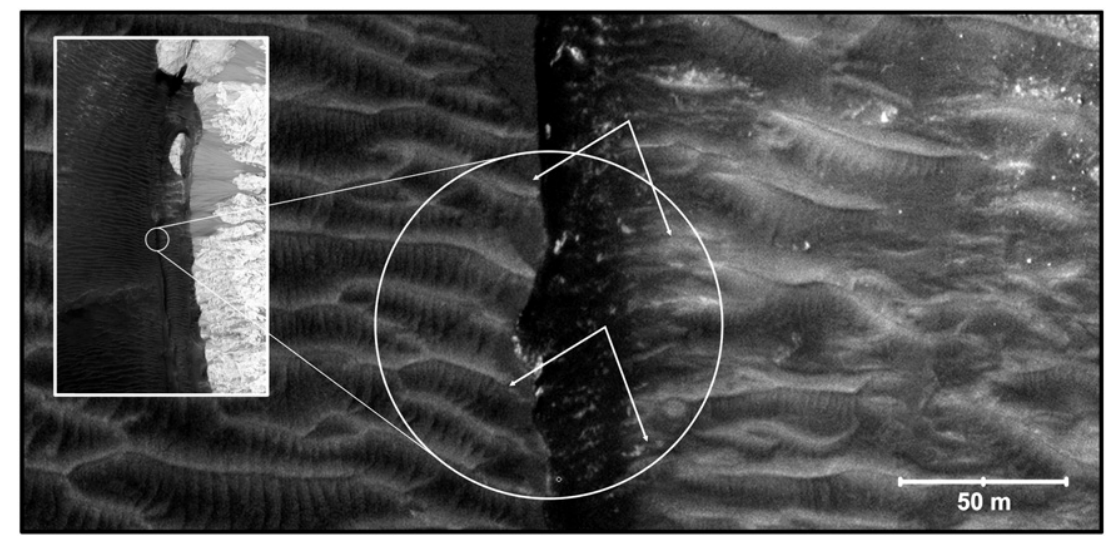

Fig. 4. Detailed view of dunes affected by the scarp. Not only do the dunes seem to be sharply interrupted, but there also seems to be a correlation between crests on both sides of the scarp. 
some patches from eolian plateau deposits at the foot of the scarp that could be interpreted as once covered the scarp, but these patches show some tilting that suggests they are not in their original position and were affected by the formation of the scarp. Even if the eolian deposits once covered the scarp, some reactivation took place that affected them. These results provide a maximum age for the Westfacing scarp and the landslide since these events postdate the "Eolian Plateau Deposits" material and must be younger than $4.43 \mathrm{Ma}$ (Fig. 5).

In order to constrain the age of the dune field we followed the main depression trend, looking for a surface where crater counting could be performed. Toward the Northeast of the landslide we found more evidence of dunes affected by another scarp. Fig. 6 shows a vertical scarp of $\sim 100 \mathrm{~m}$ located $7 \mathrm{~km}$ away from the landslide (see Fig. 1 for location) where dune crests are seen on an elevated paleosurface (Fig. 6). Although the elevated dunes on the scarp shoulder could be unrelated to those at the bottom, linear crests above and below the scarp match almost perfectly. Moreover the high crests are thinner and more degraded than the dunes below as a consequence of differences in wind patterns and sediment supply. This sediment supply is generated by the scarp itself as can be seen in Fig. 6, where falling material is partially covering dunes below. At the top of the scarp, dune deposits overlay a cratered material

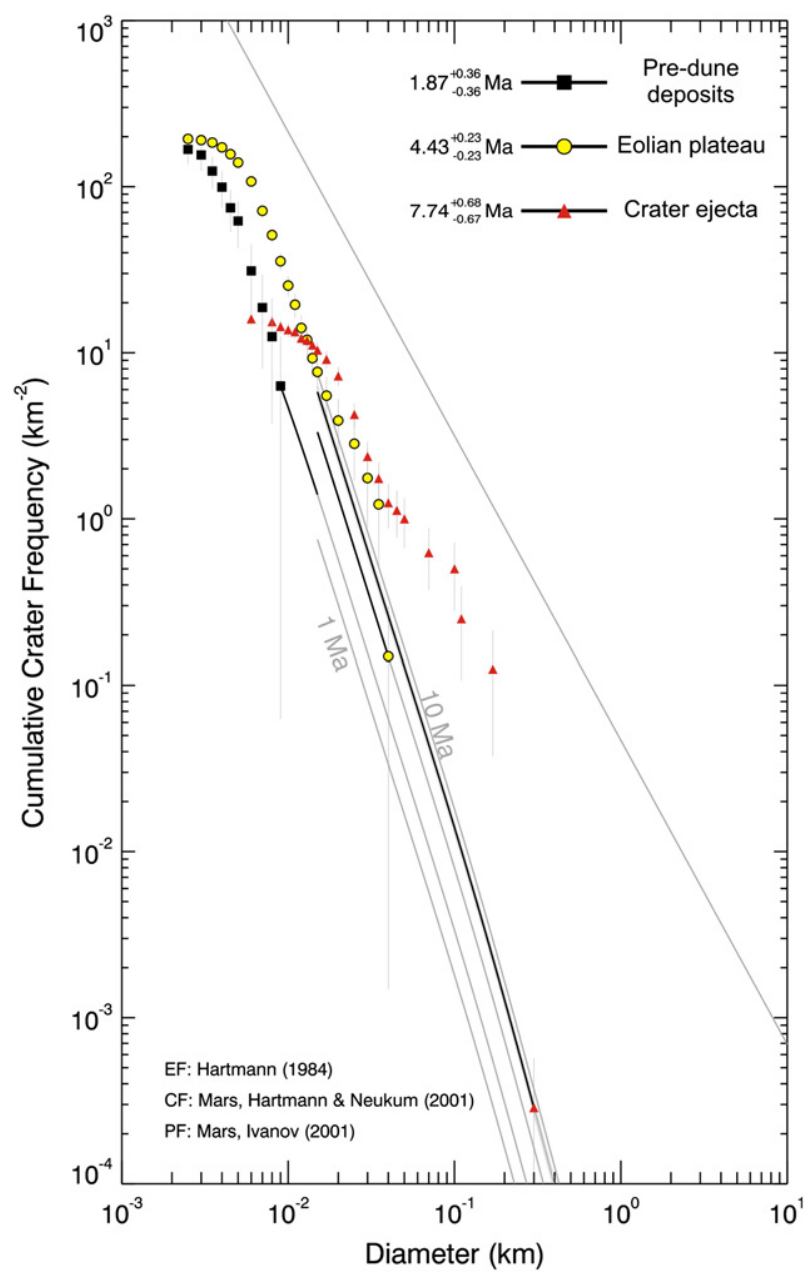

Fig. 5. Model ages derived from crater statistics for three surfaces. Two of them were found on top of the plateau above the landslide, and the third one below the dune deposits. Crater model ages appear to be very young, and represent a maximum age for the landslide of $1.87 \mathrm{Ma}$. (See text for details of age determination and Ancillary Fig. 1 for location).Model ages derived from crater statistics for three surfaces. Two of them were found on top of the plateau above the landslide, and the third one below the dune deposits. Crater model ages appear to be very young, and represent a maximum age for the landslide of $1.87 \mathrm{Ma}$. (See text for details of age determination and Ancillary Fig. 1 for location). which we term "Pre-dune Material", for which an age of $1.87 \mathrm{Ma}$ age was determined by crater counting (Fig. 5).

\section{Structural analysis}

In this section we focus on the small antithetic scarp that affected the landslide deposits (Figs. 2a and 7). Following the hypothesis that scarps were produced by high angle normal faults, we measured the necessary displacement needed to accommodate the topographic vertical offset. In order to do that, and because of the lack of highresolution topography in the area, we use two independent methods to estimate the displacement across the smaller scarp. The first method consists of counting the number of pixels covering the scarp width in the HIRISE image, considering that no scarp retreat by erosion has taken place, thus determining the horizontal extension (d). After counting the number of pixels across-scarp at several locations along the scarp trend, we obtained a range for horizontal displacements (d) between 10.5 and $20 \mathrm{~m}$, which implies a vertical offset between 18.18 and $34.64 \mathrm{~m}$ respectively by assuming a $60^{\circ}$ fault inclination. By assuming a $70^{\circ}$ inclination, fault offset values change to 28.8 and $54.9 \mathrm{~m}$ respectively (Fig. 7a).

The second method uses a MOLA profile that crosses the area. We could calculate the minimum vertical offset between the graben floor and the regional level on the surroundings independently of any structural model (Fig. 7b and c).

We obtained a topographic vertical offsets between 25 and $30 \mathrm{~m}$ (Fig. $7 \mathrm{~b}$ and c). This is in agreement with the values obtained using the first method.

Finally, combining both independent measurements of horizontal displacement (d) from the plan view and from the vertical offset measured in MOLA data, we can estimate the fault inclination, which gives values between $56^{\circ}$ and $67^{\circ}$. Dip angles of normal faults reported in the literature are closer to $70^{\circ}$ or even more in terrestrial rift zones (Gudmundsson, 1992). Also, many faults in basalt layers start growing as a tension fracture at surface and propagate downward until a critical depth where the structure continues as a fault (Acocella et al., 2003; Holland et al., 2006). Our results show that this small structure is likely to have a high dip angle rather than the $60^{\circ}$ angle usually mentioned in literature (e.g. Golombek et al., 1996).

Using profiles derived from high-resolution DEM and the HIRISE image, we constructed a structural section using $70^{\circ}$ dipping faults in order to measure finite extension (Fig. 7d). We calculated extension values individually for the West and East-facing scarps along an arbitrary distance extending far beyond the structures. For the West-facing scarp and the East-facing antithetic scarp we obtained extension values of $155 \mathrm{~m}$ and $16 \mathrm{~m}$, respectively. The $16 \mathrm{~m}$ of displacement for the smaller scarp is comparable with the direct measurements described in Fig. 7a. When comparing the maximum measured displacement value with the length of the fault (Fig. 1 and Ancillary Fig. 2) we found that the displacement-to-length ratio is near 0.005. Although this value is relatively low, it is in the order of previously reported ratios, which are typically between 0.006 and 0.0067 for faults on Mars (Schultz et al., 2010). The lower ratio reported here could be a consequence of the fact that displacement measurements were only possible in certain locations off the center of the scarp where the maximum displacement is expected (see Ancillary Fig. 2 for location).

\section{Interpretation and discussions}

The slope of a scarp is a function of its age (e.g., Wallace, 1977). Although this notion cannot be directly applied to Mars, the location of the fresh-looking aprons and the landslide deposit at the steeper sections of the scarp implies that they may represent the youngest events in the area. Moreover, the absence of gullies and incisions on the aprons suggests that they have a dry mass-wasting origin. The texture of the "Debris Cone I" unit suggests that they are probably 

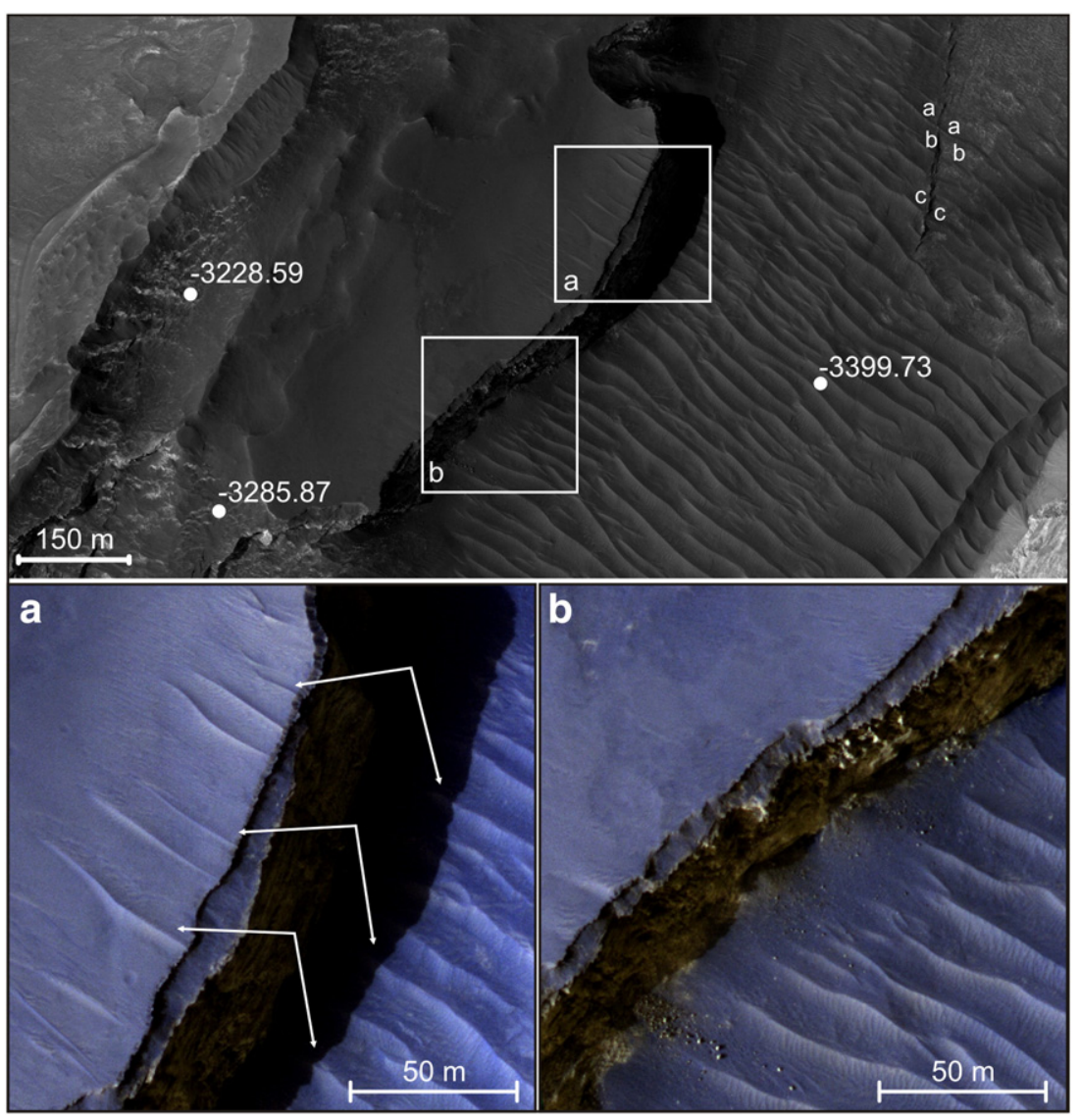

Fig. 6. Detail of HIRISE image PSP_003103_1765; centered at $3.53^{\circ} \mathrm{S} 332.63^{\circ} \mathrm{E}$ showing another topographic scarp; (see Fig. 1 for location). White dots represent MOLA PEDR points with altitude values. (a) Dunes affected by the scarp. Note the conformance between crests above and below the scarp. (b) Falling sediment (e.g., boulders) from the scarp covering dunes.

composed of Light Toned Deposits material, as compared to the "Debris Cone II" unit which may be composed of sediments from the "Eolian Plateau Deposits" above LTD and/or dark-grained material observed between layers. All these debris cones and landslide processes resemble mass movements in dry environments.

The landslide and its regional setting resemble terrestrial avalanches in dry environments on Earth. An example of these processes is found in the Argentinian Southern Puna, which is a high plateau of $4 \mathrm{~km}$ elevation. This area is characterized by volcanic features, salt deposits and extensional features associated with bimodal volcanism (e.g., Kraemer et al., 1999). Landslides and rock avalanches in this region are typically triggered by tectonic events (Hermanns et al., 2001). In one of the lineaments of the western margin of the Sierra de Calalaste $50 \mathrm{~km}$ South-West from Antofagasta de la Sierra we found a landslide deposit with similar characteristics to the one found on Mars (Fig. 8). Both deposits have rounded shape in plan view, and are situated under a characteristic headscarp. Although the terrestrial example is more eroded than the example from Mars, the knobby nature from terrestrial avalanches can be recognized at both deposits. The terrestrial case example is clearly affected by a normal fault, generating a fracture and a wind corridor, which is analogous to the one found in the Martian landslide. In both cases, the deposits are also lightly deflected following the regional slope, toward North in the example of the Earth and toward South in the example of Mars.

Linear scarps are commonly associated with faults, which usually appear relatively fresh on Mars as compared to Earth due to the lack of intense exogenic erosion in recent times. Nevertheless, it is difficult to observe pristine fault planes because mass wasting processes usually degrade scarps. Most models of chaotic terrains and
LTD origin invoke a relation with extensional faults, either on local (Zegers et al., 2010) or regional (Rodriguez et al., 2005) scale. Our observations provide direct evidence of mass wasting deposits and perhaps dunes affected by faults. The absence of impact craters on the landslide deposits together with the evidence that the East-facing scarp is affecting dunes suggests that this mass-wasting process has occurred very recently, probably less than $2 \mathrm{Ma}$ ago, and perhaps even less than 100,000 years ago, based on dune ages (Bourke et al., 2008; Chojnacki et al., 2011; Greeley, 2002; Reiss et al., 2004; Silvestro et al., 2010).

\section{Conclusions}

We conclude that: a) scarps were produced by high-angle extensional faults, b) there are at least two clear situations in the study area where faulting activity affected eolian deposits, and subsidence occurred in recent times, c) the scarps could have evolved in an analogous manner to scarps associated with foot-hill grabens as described by Wallace (1977) (Fig. 9).

LTD in Aureum Chaos is characterized by plateau morphologies bounded by steep scarps. Despite near-vertical walls and the fact that they might be composed by erodible materials, very little or no debris material is seen at the foot of the scarps. The very recent fault activity and subsidence in Aureum Chaos might have created accommodation space that eventually was filled by younger material. This conclusion may also favor the hypothesis that relates chaotic terrains and LTD with faulting and previous structural controls (Meresse et al., 2008; Okubo, 2010).

We presented evidence that scarps associated with the edge of LTD in Aureum Chaos could be related to deep structures that may have controlled subsidence and may be potentially still active on 


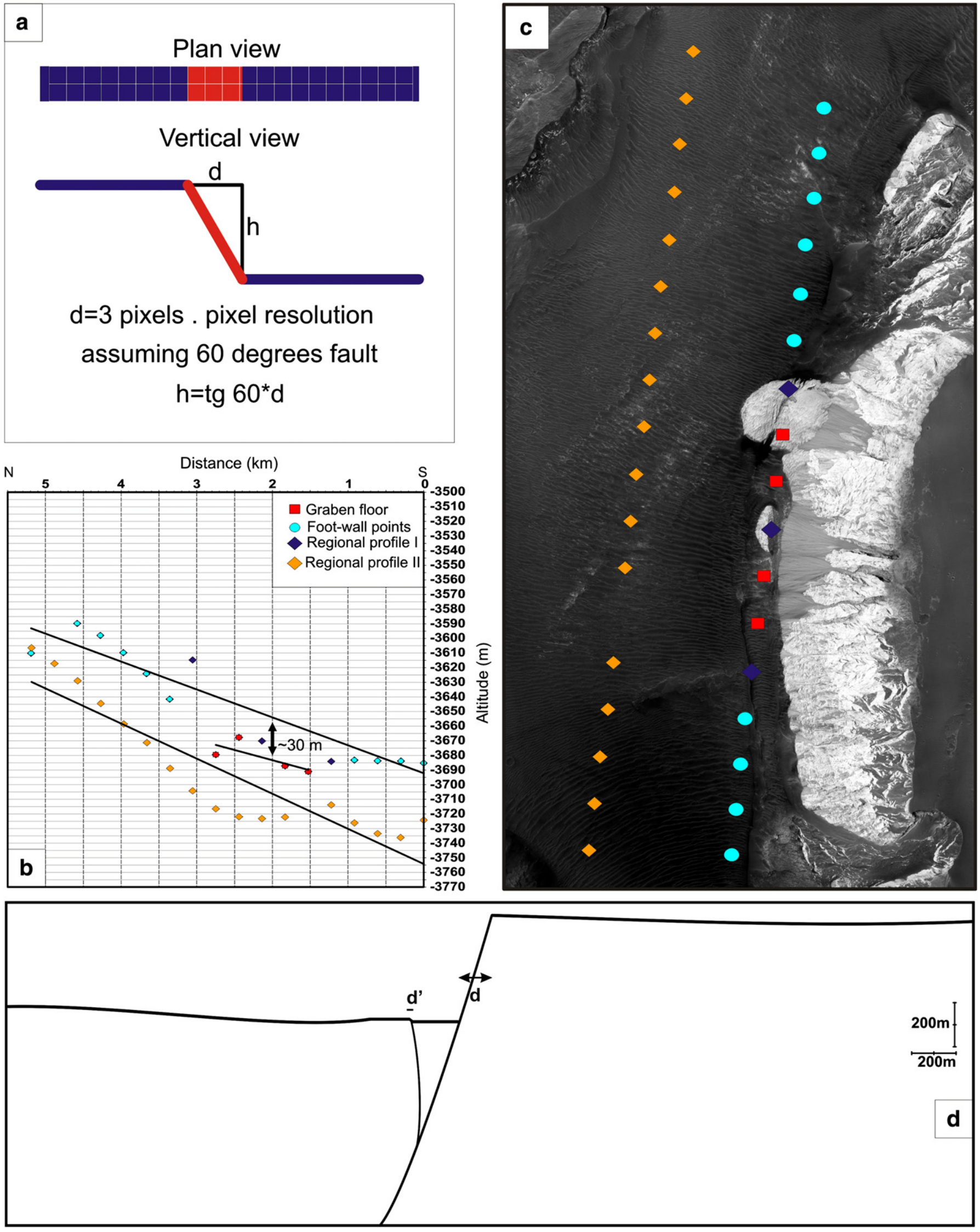

Fig. 7. Extension measurements and structural cross-section. (a) Schematic sketch to illustrate how the horizontal extension was measured on a HIRISE image. (b) Two MOLA profiles, one crossing the graben and the other one (dots) next to the graben on the surrounding plain, were used to calculate the regional slope. Squares represent the hanging wall block and the floor of the graben. The vertical distance between these two points was used as vertical offset. (c) Location of the MOLA profiles. (d) Structural section constructed to measure finite strain rates in the area. Initial distance was arbitrarily taken between two points far from the graben. The section represents an almost vertical fault-type structure with conjugated faults (Schultz et al. 2010). 


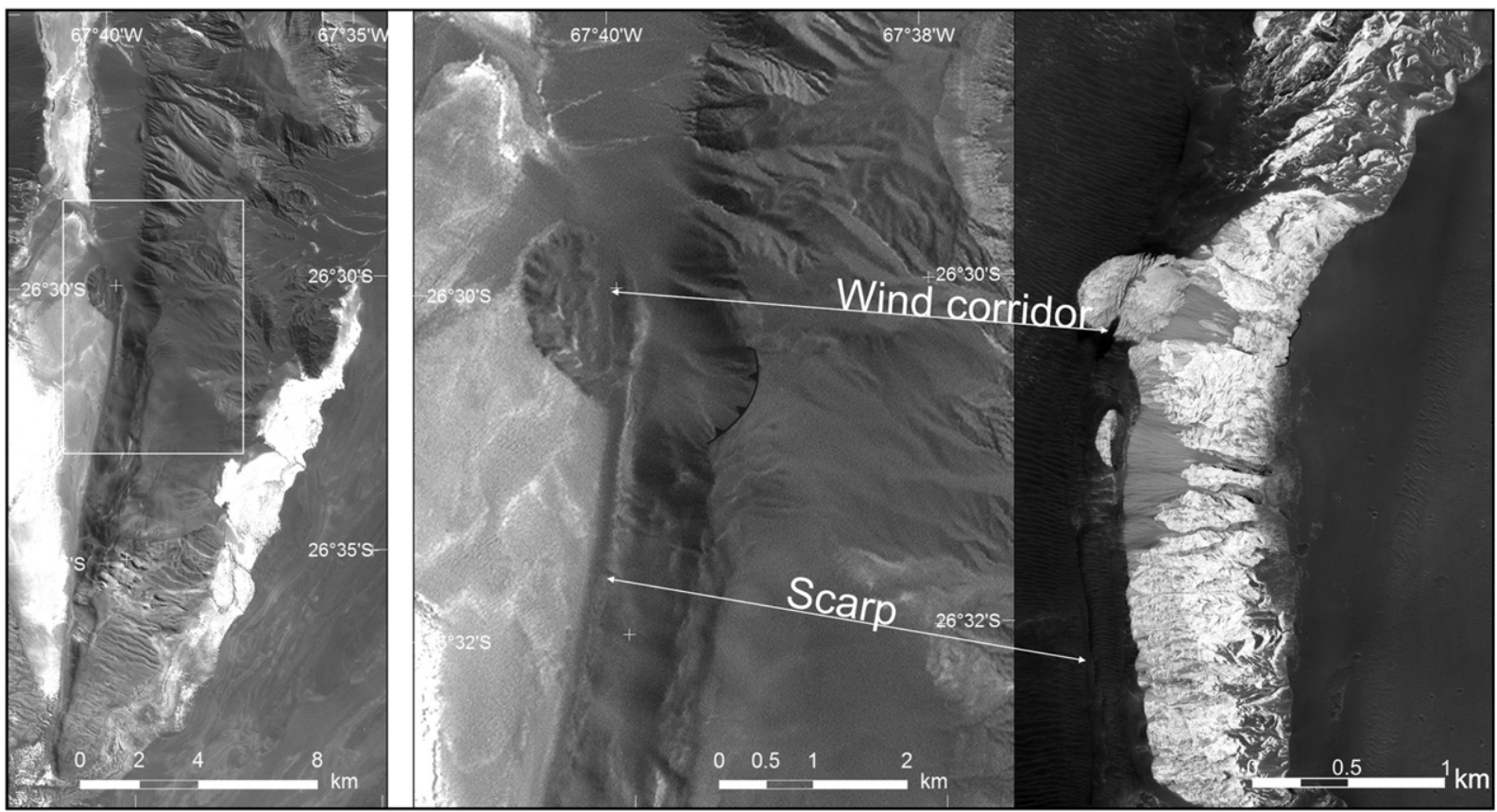

Fig. 8. Comparison between a landslide on Earth (left and middle) (Landsat TM) and Mars (right). The terrestrial example is located in the Argentinian Puna in a very dry region centered at $26^{\circ} 30^{\prime} 9.74^{\prime \prime} \mathrm{S}$ and $67^{\circ} 40^{\prime} 5.18^{\prime \prime} \mathrm{W}$.

Mars. This kind of activity has not been reported before, and has several implications on the origin of Aureum Chaos in particular, and the recent geomorphological evolution of Mars in general. We predict that more examples of such activity might be found by inspecting HIRISE images and extremely high-resolution DEM in other chaotic terrains. Such observations would help to understand which parts of Mars are more dynamic, for example for future geophysical exploration, or seismic network missions (Banerdt et al., 2010; Harri et al., 1999; Knapmeyer et al., 2006). Moreover, the fact that there is recent tectonic activity and subsidence may also be of interest for the study of subsurface fluid and gas
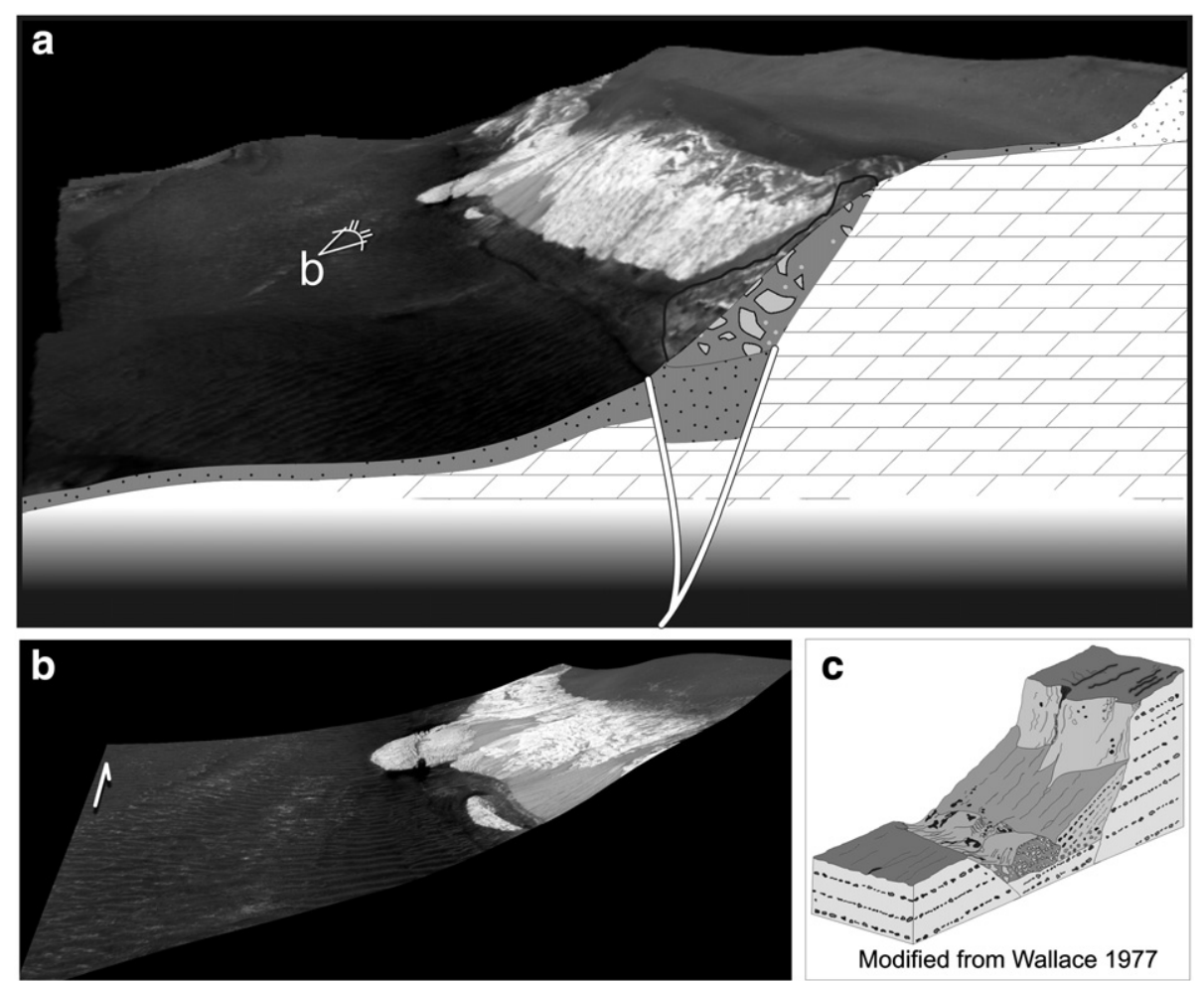

Fig. 9. Block diagram of the scarp constructed from HIRISE (PSP_006004_1765) image and HRSC DEM. (a) South-north view of the main scarp and the East-facing antithetic scarp forming a graben at the base. (b) Detail of the deposits affected by the smaller scarp. (c) Model from Wallace (1977) showing a graben at the base of a scarp. 
circulation at near-surface and possible recent or present-day gas emission zones (Komatsu et al., 2011; Wray and Ehlmann, 2011)

Supplementary materials related to this article can be found online at doi:10.1016/j.epsl.2011.09.052

\section{Acknowledgments}

This work has been possible thanks to financial and logistical support of the International Space Science Institute in Bern and the COSPAR Capacity Building Fellowship Program. This is contribution R-08 of the Instituto de Estudios Andinos Don Pablo Groeber. The study was partly funded by the Helmholtz Alliance "Planetary Evolution and Life". Alexander Dumke produced the regional multi-orbit HRSC stereo-derived DEM. The efforts of the HRSC, MOLA, MOC, THEMIS, CTX, and HiRISE teams for making data available to the public through PDS are highly appreciated. We are grateful to the reviewers Chris Okubo and Victor Baker for their useful comments, which improved the manuscript significantly. We also thank Alfonsina Tripaldi for the discussions and the ISSI Interior Layered Deposits (ILD) Team activities, under which this effort started.

\section{References}

Acocella, V., Korme, T., Salvini, F., 2003. Formation of normal faults along the axial zone of the Ethiopian Rift. J. Struct. Geol. 25, 503-513.

Balme, M., Berman, D., Bourke, M., Zimbelman, J., 2008. Transverse aeolian ridges (TARs) on Mars. Geomorphology 101 (4-1), 703-720.

Banerdt, B., Cox, Z.N., Seybold, C., Warwick, R., Barry, S., Hudson, T.L., Hurst, K.J., Kobie, B., Sklyanskiy, E., 2010. Geophysical Monitoring Station (GEMS): A Discovery-Class Mission to Explore the Interior of Mars. American Geophysical Union. Fall Meeting 2010, abstract \#DI43A-1938.

Basilevsky, A.T., Werner, S.C., Neukum, G., Head, J.W., van Gasselt, S., Gwinner, K., Ivanov, B.A., 2006. Geologically recent tectonic, volcanic and fluvial activity on the eastern flank of the Olympus Mons volcano, Mars. Geophys. Res. Lett. 33, L13201. doi:10.1029/2006GL026396.

Bourke, M.C., Edgett, K.S., Cantor, B.A., 2008. Recent aeolian dune change on Mars. Geomorphology 94 (1-2), 247-255.

Chojnacki, M., Burr, D.M., Moersch, J.E., Michaels, T.I., 2011. Orbital observations of contemporary dune activity in Endeavor crater, Meridiani Planum, Mars. J. Geophys. Res. 116, E00F19. doi:10.1029/2010JE003675.

Diniega, S., Byrne, S., Bridges, N.T., Dundas, C.M., McEwen, A.S., 2010. Seasonality of present-day Martian dune-gully activity. Geology 38 (11), 1047-1050. doi:10.1130/G31287.1.

Dobrea, E.N., Poulet, F., Malin, M., 2008. Correlations between hematite and sulfates in the chaotic terrain east of Valles Marineris. Icarus 193 (2), 516-534.

Dohm, J.M., Anderson, R.C., Barlow, N.G., Miyamoto, H., Davies, A.G., Taylor, G.J., Baker, V.R., Boynton, W.V., Keller, J., Kerry, K., Janes, D., Fairen, A.G., Schulze-Makuch, D., Glamoclija, M., Marinangeli, L., Ori, G.G., Strom, R.G., Williams, J.P., Ferris, J.C., Rodriguez, J.A.P., de Pablo, M.A., Karunatillake, S., 2008. Recent geological and hydrological activity on Mars: next term the Tharsis/Elysium corridor. Planet. Space Sci. 56 (7), 985-1013.

Glotch, T.D., Rogers, A.D., 2007. Evidence for aqueous deposition of hematite- and sulfate-rich light-toned layered deposits in Aureum and Iani Chaos, Mars. J. Geophys. Res. 112, E06001. doi:10.1029/2006JE002863.

Golombek, M.P., Tanaka, K.L., Franklin, B.J., 1996. Extension across Tempe Terra Mars, from measurements of fault scarp widths and deformed craters. J. Geophys. Res. $101,26119-26130$.

Greeley, R., 2002. Saltation impact as a means for raising dust on Mars. Planet. Space Sci. 50 (2), 151-155.

Gudmundsson, A., 1992. Formation and growth of normal faults at the divergent plate boundary in Iceland. Terra Nova 4, 464-471.

Harri, A.-M., Marsal, O., Lognonne, P., Leppelmeier, G.W., Spohn, T., Glassmeier, K.-H., Angrilli, F., Banerdt, W.B., Barriot, J.P., Bertaux, J.-L, Berthelier, J.J., Calcutt, S., Cerisier, J.C., Crisp, D., Dehant, V., Giardini, D., Jaumann, R., Langevin, Y., Menvielle, M., Musmann, G., Pommereau, J.P., Di Pippo, S., Guerrier, D., Kumpulainen, K., Larsen, S., Mocquet, A., Polkko, J., Runavot, J., Schumacher, W., Siili, T., Simola, J., Tillman, J.E., NetLander Team, 1999. Network science landers for Mars. Adv. Space Res. 23 (11), 1915-1924. doi:10.1016/S0273-1177(99)00279-3 The Moon and Mars.

Hartmann, W.K., Neukum, G., 2001. Cratering chronology and the evolution of Mars. Space Sci. Rev. 96, 65-194 April.

Hartmann, W.K., Quantin, C., Werner, S., Popova, O., 2010. Do young Martian ray craters have ages consistent with the crater count system? Icarus 208, 621-635. doi:10.1016/ j.icarus.2010.03.030.

Hauber, E., Brož, P., Jagert, F., Jodłowski, P., Platz, T., 2011. Very recent and widespread basaltic volcanism on Mars. Geophys. Res. Lett. 38, L10201. doi:10.1029/2011GL047310.

Head, J.W., Mustard, J.F., Kreslavsky, M.A., Milliken, R.E., Marchant, D.R., 2003. Recent ice ages on Mars. Nature 426, 797-802.
Hermanns, R.L., Niedermann, S., Villanueva Garcia, A., Sosa Gomez, J., Strecker, M.R 2001. Neotectonics and catastrophic failure of mountain fronts in the southern intra-Andean Puna Plateau, Argentina. Geology 29, 619-623.

Holland, M., Urai, J.L., Martel, S., 2006. The internal structure of fault zones in basaltic sequences. Earth Planet. Sci. Lett. 248 (1-2), 301-315.

Ivanov, B.A., 2001. Mars/moon cratering rate ratio estimates. Space Sci. Rev. 96, 87-104.

Kereszturi, A., Möhlmann, D., Berczi, Sz, Ganti, T., Kuti, A., Sik, A., Horvath, A., 2009. Recent rheologic processes on dark polar dunes of Mars: driven by interfacial water? Icarus 201 (2), 492-503.

Knapmeyer, M., Oberst, J., Hauber, E., Wählisch, M., Deuchler, C., Wagner, R., 2006. Working models for spatial distribution and level of Mars' seismicity. J. Geophys. Res. 111, E11006. doi:10.1029/2006JE002708.

Kneissl, T., van Gasselt, S., Neukum, G., 2011. Map-projection-independent crater sizefrequency determination in GIS environments - new software tool for ArcGIS. Planet. Space Sci. 59 (11-12), 1243-1254.

Komatsu, G., Ori, G.G., Cardinale, M., Dohm, J.M., Baker, V.R., Vaz, D.A., Ishimaru, R., Namiki, N., Matsui, T., 2011. Roles of methane and carbon dioxide in geological processes on Mars. Planet. Space Sci. 59 (2-3), 169-181. doi:10.1016/j.pss.2010.07.002.

Kraemer, B., Adelmann, D. Alten, M. Schnurr, W., Erpenstein, K., Kiefer, E., van den Bogaard, P., Görler, K., 1999. Incorporation of the Paleogene foreland into the Neogene Puna Plateau, the Salar de Antofalla area, NW Argentina. J. South Amer. Earth Sci. 12, 157-182.

Marquez, A., Fernandez, C., Anguita, F., Farelo, A., Anguita, J., de la Casa, M.A., 2004. New evidence for a volcanically, tectonically, and climatically active Mars. Icarus 172 (2), 573-581.

McEwen, A.S., Bierhaus, E., 2006. The importance of secondary cratering to age constraints on planetary surfaces. Annu. Rev. Earth Planet. Sci. 34, 535-567.

McEwen, A.S., Preblich, B.S., Turtle, E.P., Artemieva, N.A., Golombek, M.P., Hurst, M., Kirk, R.L., Burr, D.M., Christensen, P.R., 2005. The rayed crater Zunil and interpretations of small impact craters on Mars. Icarus 176, 351-381. doi:10.1016/j.icarus.2005.02.009.

McEwen, A.S., Ojha, L., Dundas, C.M., Mattson, S.S., Byrne, S., Wray, J.J., Cull, S.C., Murchie, S.L., Thomas, N., Gulick, V.C., 2011. Seasonal flows on warm Martian slopes. Science 333 (6043), 740-743. doi:10.1126/science.1204816.

Meresse, S., Costard, F., Mangold, N., Masson, P., 2008. Formation and evolution of the chaotic terrains by subsidence and magmatism: Hydraotes Chaos, Mars. Icarus 194 (2), 487-500.

Michael, G.G., Neukum, G., 2010. Planetary surface dating from crater size-frequency distribution measurements: partial resurfacing events and statistical age uncertainty. Earth Planet. Sci. Lett. 294, 223-229. doi:10.1016/j.epsl.2009.12.041.

Morgan, G.A., Head, J.W., Forget, F., Madeleine, J.B., Spiga, A., 2008. Gully formation on Mars: two recent phases of formation suggested by links between morphology, slope orientation and insolation history. Icarus 208 (2), 658-666.

Nelson, D.M., Greeley, R., 1999. Geology of Xanthe Terra outflow channels and the Mars Pathfinder landing site. J. Geophys. Res. 104, 8653-8669.

Neukum, G., Jaumann, R., Hoffmann, H., Hauber, E., Head, J.W., Basilevsky, A.T., Ivanov, B.A., Werner, S.C., van Gasselt, S., Murray, J.B., McCord, T., Co-Investigator Team, H.R.S.C., 2004. The Recent and episodic volcanic and glacial activity on Mars revealed by the High Resolution Stereo Camera. Nature 432, 971-979.

Okubo, C.H., 2010. Structural geology of Amazonian-aged layered sedimentary deposits in southwest Candor Chasma, Mars. Icarus 207, 210-225.

Quantin, C., Allemand, P., Mangold, N., Delacourt, C., 2004. Ages of Valles Marineris (Mars) landslides and implications for canyon history. Icarus 172 (2), 555-572.

Reiss, D., van Gasselt, S., Neukum, G., Jaumann, R., 2004. Absolute dune ages and implications for the time of formation of gullies in Nirgal Vallis, Mars. J. Geophys. Res. 109, E06007. doi:10.1029/2004JE002251.

Rodriguez, J.A.P., Sasaki, S., Kuzmin, R.O., Dohm, J.M., Tanaka, K., Miyamoto, H., Kurita, K., Komatsu, G., Fairen, A.G., Ferris, J.C., 2005. Outflow channel sources, reactivation, and chaos formation, Xanthe Terra, Mars. Icarus 175 (1), 36-57. doi:10.1016/ j.icarus.2004.10.025.

Rodriguez, J.A.P., Kargel, J., Crown, D.A., Bleamaster III, L.F., Tanaka, K.L., Baker, V., Miyamoto, H., Dohm, J.M., Sasaki, S., Komatsu, G., 2006. Headward growth of chasmata by volatile outbursts, collapse, and drainage: evidence from Ganges chaos, Mars. Geophys. Res. Lett. 33, L18203. doi:10.1029/2006GL026275.

Rossi, A.P., Neukum, G., Pondrelli, M., van Gasselt, S., Zegers, T., Hauber, E., Chicarro, A., Foing, B., 2008. Large-scale spring deposits on Mars? J. Geophys. Res. 113, 1-17.

Schultz, R.A. Hauber, E., Kattenhorn, S.A., Okubo, C.H., Watters, T.R., 2010. Interpretation and analysis of planetary structures. J. Struct. Geol. 32, 855-875.

Silvestro, S., Fenton, L.K., Vaz, D.A., Bridges, N.T., Ori, G.G., 2010. Ripple migration and dune activity on Mars: evidence for dynamic wind processes. Geophys. Res. Lett. 37. L20203. doi:10.1029/2010GL044743.

Wallace, R.E., 1977. Profiles and ages of young fault scarps, north-central Nevada. Geol. Soc. Am. Bull. 88, 1267-1281.

Werner, S.C., Ivanov, B.A., Neukum, G., 2009. Theoretical analysis of secondary cratering on Mars and an image-based study on the Cerberus Plains. Icarus 200, 406-417. doi:10.1016/j.icarus.2008.10.011.

Wray, J.J., Ehlmann, B.L., 2011. Geology of possible Martian methane source regions. Planet. Space Sci. 59, 196-202.

Zegers, T.E., Oosthoek, J.H.P., Rossi, A.P., Blom, J.K., Schumacher, S., 2010. Melt and collapse of buried water ice: an alternative hypothesis for the formation of chaotic terrains on Mars. Earth Planet. Sci. Lett. 297 (3-4), 496-504. doi:10.1016/j.epsl.2010.06.049 1,. 